\title{
Mechanical Properties and Crystallographic Texture of Symmetrical and Asymmetrical Cold Rolled IF Steels
}

\author{
Nina do Amaral Sardinha ${ }^{a}$, Igor Cuzzuol dos Santos ${ }^{a}$, Bárbara Vaz Andrade $^{a}$, Ramón Alves Botelho , \\ Rebeca Vieira de Oliveira ${ }^{a}$, Saulo Brinco Diniz ${ }^{a, b}$, Andersan dos Santos Paula ${ }^{a}$ Luiz Paulo Brandao * \\ ${ }^{a}$ Seção de Engenharia Mecânica e de Materiais, Instituto Militar de Engenharia, Praça General \\ Tibúrcio, 80, 22290-270, Praia Vermelha, Rio de Janeiro, RJ, Brasil. \\ ${ }^{b}$ Centro Federal de Educação Tecnológica Celso Suckow da Fonseca-CEFET, RJ, Angra dos Reis, RJ, Brasil
}

Received: August 7, 2015; Revised: June 26, 2016; Accepted: July 14, 2016

\begin{abstract}
The crystallographic texture developed during cold rolling and subsequent annealing of interstitial free sheet steels aims to increase conformability. For this, it is necessary to obtain partial $\alpha$-fiber and continuous and homogeneous $\gamma$-fiber texture components. In this work, the influence of symmetric (SR) and asymmetric (AR) cold rolling on crystallographic texture and mechanical properties of an interstitial free steel (IF) was investigated. Symmetric cold rolling yields $\alpha$ - and $\gamma$-fibers, which are enhanced as deformation increases. Moreover, $\alpha$-fiber weakening occurs due to recrystallizations, improving formability. The same fibers are produced by asymmetric cold rolling, but in this case, the $\gamma$-fiber is slightly shifted in psi, which is one of Euler angles second ROE's notation ${ }^{1,2}$, and more homogeneous than in symmetric rolling. The best mechanical properties were achieved by asymmetric cold rolling/annealed with about $80 \%$ deformation.
\end{abstract}

Keywords: IF Steels, Asymmetrical Cold Rolling, Texture, Mechanical Properties, Symmetrical Cold Rolling, Formability

\section{Introduction}

Interstitial free steels (IF) are widely used in the automotive industry ${ }^{3,4}$ thanks to their low tensile strength (100 to $350 \mathrm{MPa}$ ) and high formability. The industry tries to improve these properties even more, through appropriate thermomechanical processes such as cold rolling and annealing.

Cold rolling is one of the techniques used to obtain preferred orientations in the material that will improve its mechanical properties, especially the formability. Cold rolling may be symmetrical or asymmetrical. In the first case, the rolls have the same diameter, the same speed and the same friction coefficient. In the second, at least one of those conditions is different, leading to an additional shear strain, which may improve the mechanical properties and the formability ${ }^{5}$.

By definition, the normal anisotropy coefficient $\left(r_{\mathrm{m}}\right.$ or $\left.\overline{\mathrm{r}}\right)$ is the planar average of $r$ value, which is the ratio of the width strain $\left(\ln \left(\mathrm{w}_{0} / \mathrm{w}\right)\right.$ to the thickness strain $\left(\ln \left(\mathrm{t}_{0} / \mathrm{t}\right)\left(\mathrm{r}=\ln \left(\mathrm{w}_{0} / \mathrm{w}\right) /\right.\right.$ $\ln \left(\mathrm{t}_{0} / \mathrm{t}\right)$, obtained by a simple tensile test $\mathrm{t}^{6}$. In this equation, $\mathrm{w}_{0}$ and $\mathrm{t}_{0}$ are the initial sample width and thickness, respectively, and $\mathrm{w}$ and $\mathrm{t}$ its width and thickness after about $15 \%$ of plastic deformation. This parameter is generally used to verify the ability of a sheet to undergo deep drawing. The larger this coefficient, the better is the formability ${ }^{7,8}$. This can be seen in Equation (1), where, $r_{0}, r_{45}, r_{90}$ are $\mathrm{r}$ values obtained for samples removed 0 ,

* e-mail: brandao@ime.eb.br
45 and $90^{\circ}$ degrees from the rolling direction and $\overline{\mathrm{r}}$ is the normal anisotropy coefficient.

$$
\bar{r}=\frac{r_{0}+2 r_{45}+r_{90}}{4}
$$

In ultra-low carbon steels, the preferred orientations are located in two main fibers: $\alpha(<110>/ /$ Rolling DirectionRD) and $\gamma\left(<111>/ /\right.$ Normal Direction-ND) ${ }^{9}$, regardless of the rolling technique ${ }^{10}$. High formability is associated with a high fraction of $\gamma$-fibers and a low fraction of $\alpha$-fibers ${ }^{11}$.

If, $r_{0}, r_{45}$ and $r_{90}$ exhibit significant differences, the "earing phenomenon" can occur, due to the planar anisotropy $(\Delta r)$ condition described by Equation (2) ${ }^{12}$ :

$$
\Delta \mathrm{r}=\frac{r_{0}+r_{90}-2 r_{45}}{2}
$$

The sheet formability is also influenced by the hardening coefficient (n), which, using Hollomon equation ${ }^{13}$ $\left(\sigma=\mathrm{K} \varepsilon^{\mathrm{n}}\right)$, is the slope of the $\ln (\sigma)$ versus $\ln (\varepsilon)$ curves in the plastic regime and numerically equal to the uniform elongation. This parameter is important for forming operations, because it measures the hardening ability of the material, i.e., its ability to homogeneously distribute deformation along the sheet surface before necking ${ }^{14}$.

This work aims to compare the effect of symmetrical and asymmetrical cold rolling in the texture and mechanical properties of an IF steel. 


\section{Experimental Procedure}

A hot-rolled IF steel with $4.9 \mathrm{~mm}$ thickness produced by Companhia Siderúrgica Nacional (CSN) - Brazil was used in this research. Its chemical composition (wt.\%) was: $0.002 \% \mathrm{C}, 0.104 \% \mathrm{Mn}, 0.011 \% \mathrm{P}, 0.06 \% \mathrm{Ti}, 0.009 \% \mathrm{~S}$, $0.003 \% \mathrm{Ni}, 0.001 \% \mathrm{Sn}, 0.035 \% \mathrm{Al}, 0.004 \% \mathrm{~N}, 0.002 \% \mathrm{Nb}$ and $\mathrm{Fe}$ is the balance.

Symmetrical (SR) and asymmetrical (AR) cold rolling were performed in a FENN MFG. Co, model D51710 Rolling Mill to 70,80 and $90 \%$ thickness reductions. The configuration for SR was two mill rolls with $133.70 \mathrm{~mm}$ diameter each (duo configuration). For the AR, upper and lower rolls with $40.18 \mathrm{~mm}$ and $31.72 \mathrm{~mm}$ diameter, respectively, were used. For analyzing the effect of annealing, after rolling, samples were annealed in a salt bath at $850^{\circ} \mathrm{C}$ for $120 \mathrm{~s}$ and cooled in air. Finally, the samples were mechanical polished to half thickness and etched by a $5 \%$ hydrofluoric acid (HF) and $95 \%$ peroxide $\left(\mathrm{H}_{2} \mathrm{O}_{2}\right)$ solution for $20 \mathrm{~s}$.

The X-ray measurements were performed on a PANalytical, X'Pert PRO MRD diffractometer using Co-K $\alpha$ radiation and yielded (110), (200) and (211) pole figures. These experimental pole figures were processed with the help of popLA software and they are presented for $0^{\circ}$ and $45^{\circ} \varphi_{2}$ sections using the Bunge notation.

In order to evaluate the mechanical properties of the annealed materials, 5 rectangular samples with dimensions of $15 \times 100 \mathrm{~mm}$, were cut for each processing condition, i.e., symmetric and asymmetric cold rolled followed by an $850^{\circ} \mathrm{C}$ during $120 \mathrm{~s}$ annealing process, on three different angles with the rolling direction: $0^{\circ}, 45^{\circ}$ and $90^{\circ}$, totalizing 90 samples. The tensile tests were conducted on an EMIC DL 10000 machine with a $3 \mathrm{~mm} / \mathrm{min}$ loading rate, following the ABNT NBR $6892-1{ }^{15}$ standard, and the yield point $\left(\sigma_{e}\right)$, tensile strength $\left(\sigma_{m}\right)$ were evaluated. The ABNT NBR $16282^{16}$ was followed for $r_{\mathrm{m}}, \Delta r$ and work hardening coefficient $(n)$ determinations. The highest and the lowest values of each measurement were discarded and the average of the others was taken as the final result.

\section{Results and Discussion}

The $\varphi_{2}=45^{\circ}$ sections of the Orientation Distribution Function (ODF) for the symmetrical cold rolled and annealed samples are shown in Figure 1. $\alpha$ - and $\gamma$-fibers can be observed for 70,80 and $90 \%$ cold rolled samples. The volume fraction of $\alpha$-fibers increases up to $90 \%$ deformation, but the volume fraction of $\gamma$-fibers is smaller for $90 \%$ deformation than for 80 $\%$ deformation. This may be related to the development of a new $<110>/ / R D$ component, which inhibits the development of $\gamma$-fibers. The effect of annealing is to decrease the volume fraction of $\alpha$-fibers and to increase the volume fraction of $\gamma$-fibers, thus increasing the formability of IF steels ${ }^{17}$. The graphs of Figure 2 illustrate the development of $\alpha$ - and $\gamma$-fibers for all symmetrical cold rolled and annealed samples.

Since the deformation of asymmetrically rolled samples is not homogenous over the sheet thickness, the texture was analyzed in three different sample positions: on the lower and upper surfaces and in the middle plane. Generally, the texture was the weakest in the lower surface and the strongest in the upper surface, where it was similar to that of symmetrically rolled samples. For comparison, Figure 3 shows the $\varphi_{2}=45^{\circ}$ ODF sections for the middle plane, where no components are observed at $\Phi=54.7^{\circ}$, the original position of the $\gamma$-fiber. In this Figure 3, it can be seen the ODF sections for annealed 70,80 and $90 \%$ asymmetrically cold rolled samples. This is taken as evidence of a shift of the position of the $\gamma$-fiber, as reported by Tóth $e t a l^{18}$. The graphs of Figure 4 show the volume concentration of $\alpha$ - and $\gamma$-fibers in asymmetrically rolled samples, before and after annealing. It can be seen that the volume fractions of $\alpha$ - and $\gamma$-fibers are smaller than in symmetrically rolled samples and that annealing decreases the volume fraction of $\alpha$-fibers and thus increases formability.

Stress-strain curves of annealed symmetrically and asymmetrically cold rolled samples are shown in Figure 5. It can be observed that the yield $\left(\sigma_{e}\right)$ and tensile $\left(\sigma_{m}\right)$ strengths increase with deformation for both symmetrically (SRXX-Y) and asymmetrically (ARXX-Y) rolled/annealed samples, where $\mathrm{XX}$ denotes the deformation degree and $\mathrm{Y}$ is the angle with which the sample was taken. Asymmetrical rolling yielded larger values of $\sigma_{e}$ and $\sigma_{m}$ values for all deformations and angles, except for SR90-0 sample, whose $\sigma_{m}$ was larger than that of asymmetrically rolled/annealed samples.

The larger tensile strength $\left(\sigma_{m}\right)$ of asymmetrically rolled samples may be due to the fact that the larger shear stress associated with asymmetrical deformation leads to grain breaking and, consequently, to a smaller grain size in the rolled sample ${ }^{19}$. Wauthier et al. ${ }^{20}$ reported that this phenomenon could be observed by EBSD. The values of $\sigma_{m}$ and $\sigma_{e}$ in this work are larger than those reported by other authors ${ }^{21,22}$.

As shown in Table 1, the work hardening coefficient $n$ decreases with increasing deformation, as might be expected if deformation becomes more and more nonhomogeneous as thickness reduction progresses. The decrease is approximately linear and, in the case of asymmetric rolling, can be described by Eq. 3, where $\% x$ is the percentage relative thickness reduction and the coefficient of determination is 0.95 .

$$
\mathrm{n}=0.9741-0.0095 \% \mathrm{x}
$$

Table 2 shows the normal and planar anisotropy of the annealed samples. The values are lower than the expected for this type of material ${ }^{23-25}$. The largest value of $r_{m}$ was 1.45 for the SR90 samples. Annealed asymmetrically rolled samples reached even lower values of $r_{m}$ values, around 1.0 . 

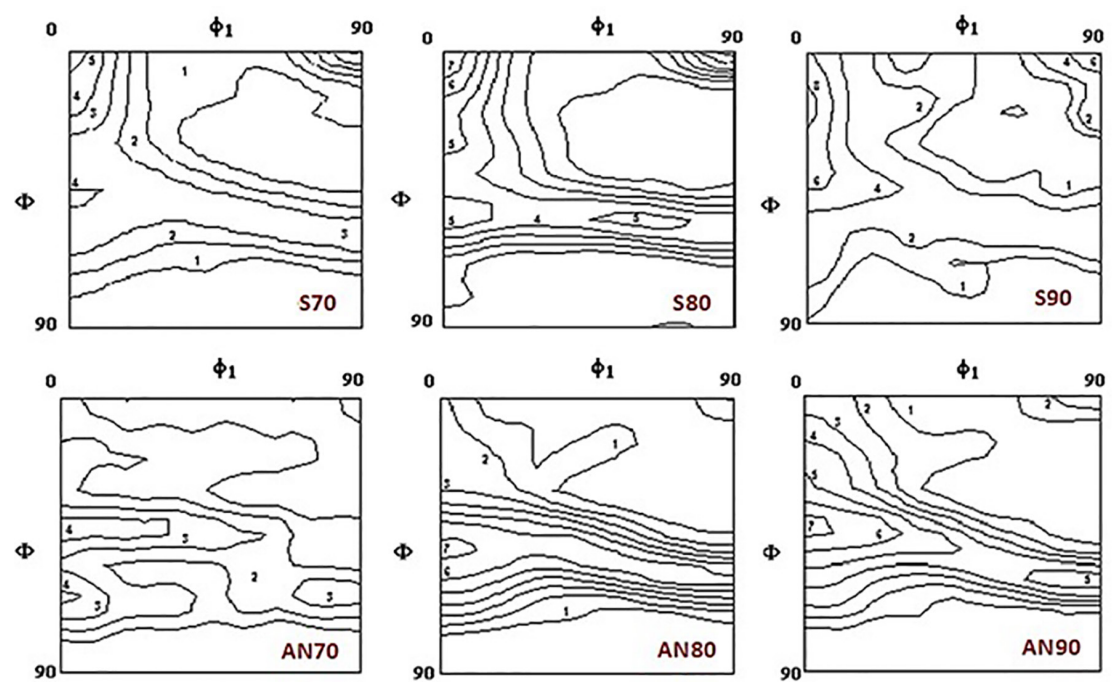

Figure 1: ODF section of $\varphi 2=45^{\circ}$ for IF steel samples symmetrically cold rolled (S) for 70,80 and $90 \%$ and after annealing (AN).
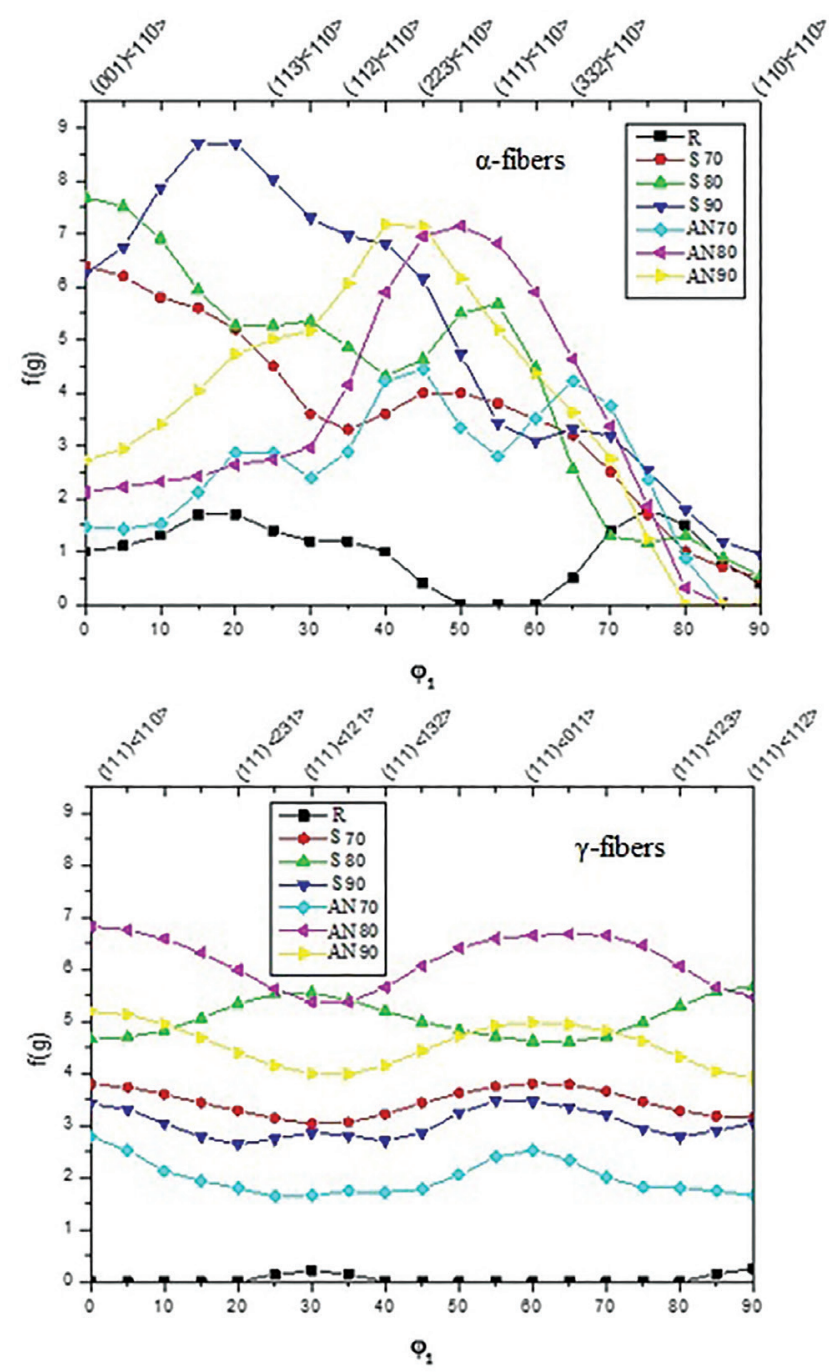

Figure 2: $\alpha$ - and $\gamma$-fibers plots for IF steel samples 70, 80 and $90 \%$ symmetrically cold rolled (S) and after annealing (AN). 

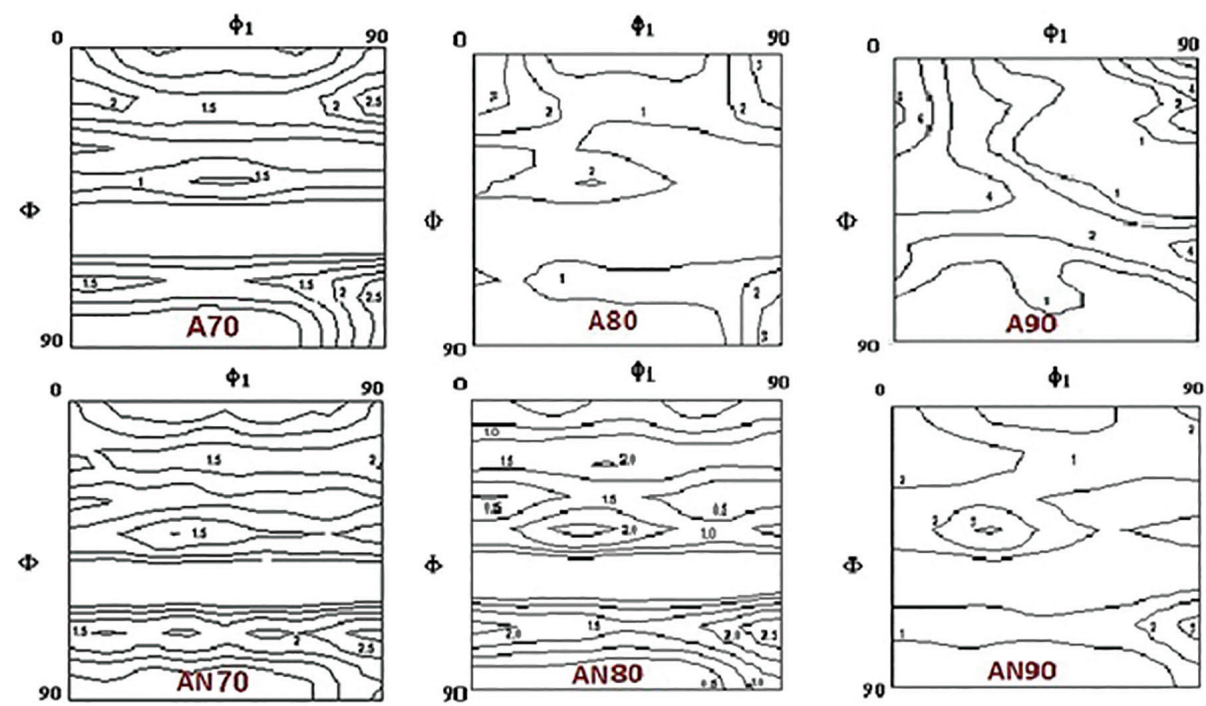

Figure 3: ODF section of $\varphi 2=45^{\circ}$ for IF steel samples asymmetrically cold rolled (A) for 70, 80 and $90 \%$ and annealed (AN).
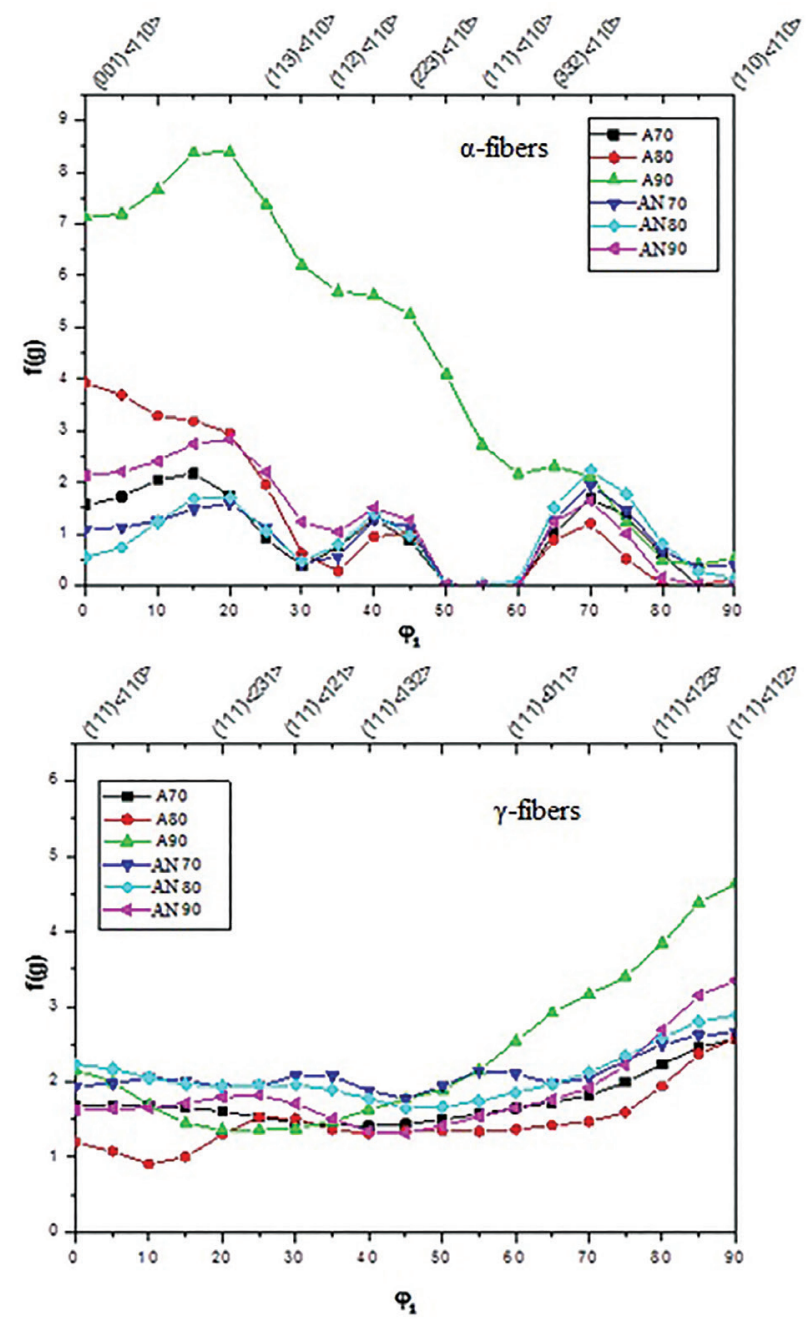

Figure 4: $\alpha$ - and $\gamma$-fiber plots for 70, 80 and $90 \%$ asymmetrically cold rolled (A) and after annealing (AN) the IF steel samples. 

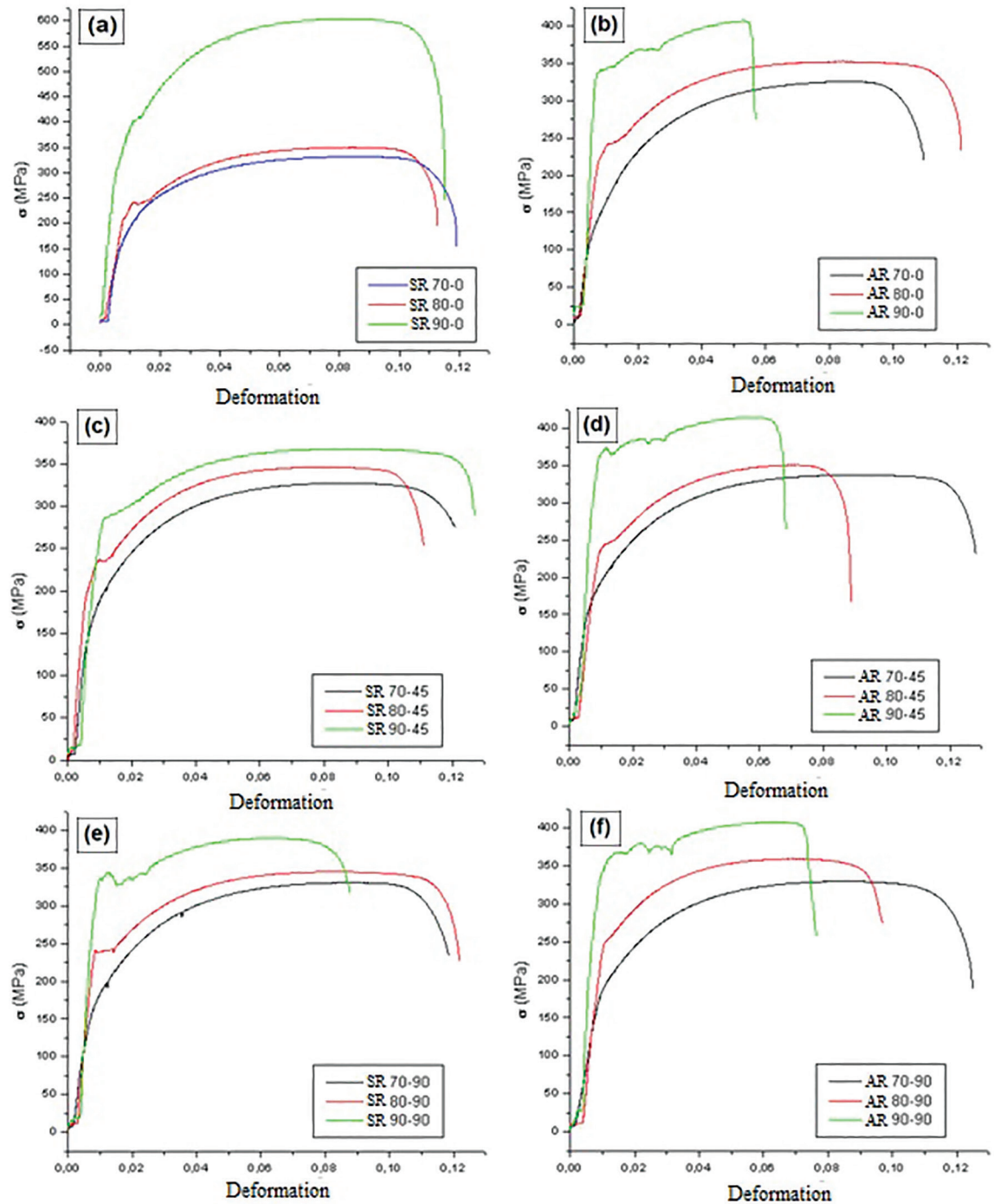

Figure 5: Engineering stress vs strain curves of annealed symmetrically rolled samples, (a) $0^{\circ} \mathrm{RD}$, (c) $45^{\circ} \mathrm{RD}$, (e) $90^{\circ} \mathrm{RD}$ and annealed asymmetrically rolled samples, (b) $0^{\circ} \mathrm{RD}$, (d) $45^{\circ} \mathrm{RD}$ e (f) $90^{\circ} \mathrm{RD}$

Table 1: Work hardening coefficient (n) of annealed symmetrically and asymmetrically cold rolled samples.

\begin{tabular}{|c|c|c|c|c|c|c|c|c|c|}
\hline \multirow[b]{2}{*}{ Cold rolling $(\%)$} & \multicolumn{9}{|c|}{ Hardening coefficient (n) } \\
\hline & \multicolumn{3}{|c|}{$70 \%$} & \multicolumn{3}{|c|}{$80 \%$} & \multicolumn{3}{|c|}{$90 \%$} \\
\hline Rolling angle & 0 & 45 & 90 & 0 & 45 & 90 & 0 & 45 & 90 \\
\hline Symmetric & 0.318 & 0.302 & 0.301 & 0.245 & 0.236 & 0.211 & 0.252 & 0.182 & 0.153 \\
\hline Asymmetric & 0.326 & 0.309 & 0.281 & 0.222 & 0.250 & 0.226 & 0.133 & 0.105 & 0.111 \\
\hline
\end{tabular}

Table 2: Normal plastic anisotropy $(\overrightarrow{\mathrm{r}})$ and planar anisotropy $(\Delta \mathrm{r})$ of annealed symmetrically (SR) and asymmetrically cold rolled samples (AR).

\begin{tabular}{lcc}
\hline & Normal plastic anisotropy & Planar anisotropy \\
\hline SR 70 & 1.29 & -0.45 \\
SR 80 & 1.22 & -0.26 \\
SR 90 & 1.45 & -0.39 \\
AR 70 & 1.25 & 0.24 \\
AR 80 & 0.99 & 0.21 \\
AR 90 & 1.06 & -0.28 \\
\hline
\end{tabular}

For all annealed symmetrically cold rolled samples and for the AR90 sample (annealed asymmetrically ones) negative values of planar anisotropy were found, while positive values were found for the AR70 and AR80 samples. The ideal planar anisotropy from the point of view of formability should be around zero, but the lowest value found in this work was 0.26 for AR80 sample. This $\Delta r$ values indicates that deep drawing test samples will show "ears" at X and Y degrees with rolling direction. 


\section{Conclusions}

The results of the present work lead to the following conclusions:

(i) The symmetrically cold rolled and annealed samples presented a typical texture of low carbon steels, consisting of partial $\alpha$-fibers and continuous $\gamma$-fibers;

(ii) The volume fraction of $\gamma$-fibers increased with deformation up to a thickness reduction of $80 \%$. A decrease in the volume fraction of $\gamma$-fibers was observed for a 90 $\%$ thickness reduction, possibly due to the appearance of new $<110>/ /$ RD components;

(iii) The texture induced by asymmetric rolling was smaller than the texture induced by symmetric rolling, but the volume fraction of $\alpha$-fibers was considerably reduced by annealing, thus increasing formability;

(iv) In the case of asymmetrically rolled/annealed samples, texture components were not found in the original position of $\gamma$-fibers, $\Phi=54.7^{\circ}$, but fibers were formed between $60<\Phi<75^{\circ}$, suggesting a displacement of $\gamma$-fibers;

(v) All deformations increased the values of the yield and strength stress; the largest increases of $\sigma_{e}$ and $\sigma_{m}$ were observed in asymmetrically rolled samples.

\section{Acknowledgments}

The authors would like to thank Companhia Siderúrgica Nacional (CSN) - Brazil, for providing the steel, Temperaço Rio - Brazil for performing the annealing treatments, CNPq and CAPES for financial supporting and Instituto Militar de Engenharia (IME) for the use of its facilities.

\section{References}

1. Roe RJ. Description of crystallite orientation in polycrystalline materials: III. General solution to pole figure inversion. Journal of Applied Physics. 1965;36(6):2024-2031.

2. Davies GJ, Goodwill DJ, Kallend JS. Charts for analysing crystallite orientation distribution function plots for cubic materials. Journal of Applied Crystallography. 1971;4:67-70.

3. Ray RK, Ghosh P, Bhattacharjee D. Effects of composition and processing parameters on precipitation and texture formation in microalloyed interstitial free high strength (IFHS) steels. Materials Science and Technology. 2009;25(9):1154-1167.

4. Banerjee K. Physical Metallurgy and Drawability of Extra Deep Drawing and Interstitial Free Steels. In: Sztwiertnia K, ed. Recrystallization. Rijeka: InTech; 2012. [Acess 2014 set 16]. Available from: http://www.intechopen.com/books/ recrystallization/physical-metallurgy-and-drawability-ofext a-deep-drawingand-interstitial-free-steels $>$. Access in: $16 / 09 / 2014$.
5. Ji YH, Park JJ. Development of severe plastic deformation by various asymmetric rolling processes. Materials Science and Engineering: A. 2009;499(1-2):14-17.

6. Lankford WJ, Snyder SC, Bauscher JA. New Criteria for Predicting the Press Performance of Deep Drawing Sheets. Transactions of the American Society of Metals. 1950;42:1197-1232.

7. Hoile S. Processing and properties of mild interstitial free steels. Materials Science and Technology. 2000;16(10):1079-1093.

8. Ray RK, Ghosh P. Texture in the design of advanced steels. Transactions of the Indian Institute of Metals. 2013;66(5):641-653.

9. Urabe T, Jonas JJ. Modeling Texture Change during the Recrystallization of an IF Steel. ISIJ International. 1994;34(5):435-442.

10. Bunge HJ. Mathematische Methoden der Texturanalyse. Berlin: Akademie-Verlag; 1969.

11. Ray RK, Jonas JJ, Hook RE. Cold rolling and annealing texture in low carbon and extra low carbon steels. International Materials Reviews. 1994;39(4):129-172.

12. Mishra S, Darmann C. Role and control of texture in deep-drawing steels. International Metals Reviews. 1982;27(1):307-320.

13. Hollomon JH. Tensile deformation. Transactions of the Metallurgical Society of AIME. 1945;162:268-290.

14. Antunes RA, Oliveira MCL. Materials selection for hot stamped automotive body parts: An application of the Ashby approach based on the strain hardening exponent and stacking fault energy of materials. Materials \& Design. 2014;63:247-256

15. Associação Brasileira de Normas Técnicas. NBR 6892-1 Materiais metálicos - Ensaio de Tração. Parte 1: Método de ensino à temperatura ambiente. Rio de Janeiro: ABNT; 2015.

16. Associação Brasileira de Normas Técnicas. NBR 16282 Folhas e chapas de aço de baixo carbono - Determinação da anisotropia plástica e do expoente de encruamento Método de ensino. Rio de Janeiro: ABNT; 2014.

17. Saha R, Ray RK. Effect of Severe Cold Rolling and Annealing on the Development of Texture, Microstructure and Grain Boundary Character Distribution in an Interstitial Free (IF) Steel. ISIJ International. 2008;48(7):976-983.

18. Tóth LS, Beausir B, Orlov D, Lapovok R, Haldar A. Analysis of texture and $R$ value variations in asymmetric rolling of IF steel. Journal of Materials Processing Technology. 2012;212(2):509-515.

19. Lapovok R, Orlov D, Timokhina IB, Pougis A, Toth LS, Hodgson PD, et al. Asymetric Rolling of Interstitial-Free Steel Using One Idle Roll. Metallurgical and Materials Transactions A. 2012;43(4):1328-1340.

20. Wauthier A, Regle H, Formigoni J, Herman G. The effects of asymmetrical cold rolling on kinetics, grain size and texture in IF steels. Materials Characterization. 2009;60(2):90-95.

21. Humane MM, Minz RK, Paretkar RK, Peshwe DR. Effect of cold rolling and mode of annealing on textures, mechanical properties and formability limit diagrams in interstitial free steel sheets. Transactions of the Indian Institute of Metals. 2010;63(6):867-880. 
22. Meira RR. Efeito da variação das condições de encharque nas propriedades mecânicas do material IF processado no recozimento contínuo da Usiminas [Dissertation]. Belo Horizonte: Universidade Federal de Minas Gerais; 2006.

23. Banerjee K, Verma AK, Venugopalan T. Improvement of Drawability of Titanium-Stabilized Interstitial-Free Steel by Optimization of Process Parameters and Texture. Metallurgical and Materials Transactions A. 2008;39(6):1410-1425.
24. Ghosh P, Bhattacharya B, Ray RK. Comparative study of precipitation behavior and texture formation in cold rolled-batch annealed and cold rolled-continuous annealed interstitial free high strength steels. Scripta Materialia. 2007;56(8):657-660

25. Dias FMS, Fonseca FAV, Hauegen CG, Lins JFC, Campos MF. Textura e comportamento mecânico de aços IF estabilizados ao Ti e Nb-Ti. Tecnologia em Metalurgia, Materiais e Mineração. 2012;9(4):294-301. 